\title{
Review of Medicinal Applications, Phytochemistry and Pharmacological Properties of Aristea ecklonii
}

\author{
Alfred Maroyi \\ Medicinal Plants and Economic Development (MPED) Research Centre, Department of Botany, University of \\ Fort Hare, Private Bag X1314, Alice 5700, South Africa
}

\begin{abstract}
Background: Aristea ecklonii is a perennial herb widely used as herbal medicine in southern Africa. Plants used as traditional medicines to treat various human diseases and illnesses play an important role in the primary healthcare of local communities in developing countries.

Purpose: The current study critically reviewed the medicinal uses, phytochemistry and pharmacological properties of $A$. ecklonii.

Methods: Literature on medicinal uses, phytochemical and pharmacological properties of $A$. ecklonii was collected from multiple internet sources including Elsevier, Google Scholar, SciFinder, Web of Science, Pubmed, BMC, Science Direct, and Scopus. Additional information was also obtained from pre-electronic sources such as books, book chapters, theses, scientific reports and journal articles obtained from the university library.

Results: This study revealed that $A$. ecklonii is used as an ornamental plant, protective charm, and herbal medicine for internal sores, cough, fever, syphilis, shingles, and venereal diseases. Ethnopharmacological research identified quinones and sterols from leaves and rhizomes of $A$. ecklonii. The crude extracts of $A$. ecklonii and the compound plumbagin isolated from the species exhibited antibacterial and antifungal activities.

Conclusion: Aristea ecklonii should be subjected to detailed phytochemical, pharmacological, and toxicological evaluations aimed at correlating its medicinal uses with its phytochemistry and pharmacological properties.
\end{abstract}

Keywords: Aristea ecklonii, Iridaceae, herbal medicine, indigenous knowledge, southern Africa.

\section{INTRODUCTION}

Aristea ecklonii Baker is a perennial herb belonging to the Iridaceae family. The genus name Aristea Sol. is derived from the Greek word "arista" which means "spike" or "point" in reference to the morphology of the leaves [1]. The specific epithet "ecklonii" is in honor of Christian Friedrich Ecklon (1795-1868), a Danish pharmacist, botanist, plant collector, and entomologist who was one of the early and most productive botanical explorers in South Africa focusing on plants used as traditional medicines and collected plants associated insects. The synonyms associated with the name $A$. ecklonii include $A$. cyanea De Wild., $A$. dichotoma Eckl. ex Klatt, $A$. lastii Baker, A. maitlandii Hutch., A. paniculata Pax and A. stipitata R.C. Foster $[2,3]$. The common English names of $A$. ecklonii include African blue star iris, aristea, blue corn-lily, blue eyes, blue iris, blue stars, blue flies, blue stars lily, and blue-eyed iris. The genus consists of about 55 species that are native to sub-Saharan and central Africa and Madagascar [4].

*Address correspondence to this author at the Medicinal Plants and Economic Development (MPED) Research Centre, Department of Botany, University of Fort Hare, Private Bag X1314, Alice 5700, South Africa; Tel: 0027719600326; E-mail: amaroyi@ufh.ac.za
Aristea ecklonii is a spreading, evergreen rhizomatous, frost-hardy perennial herb growing up to $70 \mathrm{~cm}$ in height $[4,5]$. The species has several leaves, mostly basal, stiff, upright, grass-like, narrowly lanceolate, sword-shaped, shorter leaves along the often branched and slightly winged stems. The flowers occur in terminal and axillary flower clusters standing above the leaves. The flowers are star-like, bright blue in colour, short-lived but produced in succession over an extensive period. The flowers develop into a threeangled capsule, oblong in shape, containing many redbrown seeds that are dispersed by wind and water. Aristea ecklonii has been recorded in well-drained soils, in woodland, shrubland, grassland, open and disturbed forest, margins of evergreen forests, coastal, montane, and streambanks and on rocky and bare land forming a dense clump that is impenetrable. The species has been recorded at an altitude ranging from $30 \mathrm{~m}$ to $1980 \mathrm{~m}$ above sea level [2-5]. The species has been recorded in Burundi, Cameroon, the Democratic Republic of Congo, Eswatini, Mozambique, Rwanda, South Africa, Tanzania, Uganda, and Zimbabwe [2-6].

\section{MATERIALS AND METHODS}

A literature search for information relevant to the medicinal uses, phytochemistry and pharmacological properties of $A$. ecklonii was carried out from July 2019

(C) 2020 SET Publisher 
to January 2020. Information was obtained from the main online scientific databases such as ScienceDirect, SciFinder, PubMed, Google Scholar, Medline, and SCOPUS. Searches were also undertaken in the University of Fort Hare library, and dissertation search engines like ProQuest, Open-thesis, OATD, and EThOS. The keywords used in the search included "Aristea ecklonii", the synonyms of the species "A. cyanea", " $A$. dichotoma", " $A$. lastii", "A. maitlandii", " $A$. paniculata" and "A. stipitata", English common names "African blue star iris", "aristea", "blue corn-lily", "blue eyes", "blue iris", "blue stars", "blue flies", "blue stars lily" and "blue-eyed iris". Additional searches were also carried out using the keywords "biological properties + Aristea ecklonii", "ethnobotany + Aristea ecklonii", "ethnomedicinal uses + Aristea ecklonir", "ethnopharmacological properties + Aristea ecklonii", "indigenous knowledge + Aristea eckloni", "medicinal uses + Aristea ecklonii", "pharmacological properties + Aristea ecklonil", "phyochemistry + Aristea ecklonii" and "traditional uses + Aristea ecklonii". Articles included in this study focused on the medicinal applications, phytochemistry and pharmacological properties of $A$. ecklonii, including details of the plant parts used and diseases treated.

\section{RESULTS AND DISCUSSION}

The leaf infusions of $A$. ecklonii are mainly used as herbal medicines for cough, fever, syphilis, and shingles [7-19] (Table 1, Figure 1). In South Africa, the whole plant parts of $A$. ecklonii are used as a protective charm and herbal medicine for internal sores [1]. The whole plant parts of $A$. ecklonii are used as herbal medicine for venereal diseases in Eswatini and South Africa [1, 11]. Aristea ecklonii is an important medicinal plant species in South Africa with roots of the species sold as herbal medicines in the informal herbal medicine markets in Gauteng and KwaZulu-Natal provinces in South Africa [19]. The leaves and rhizomes of three Aristea species, namely $A$. cognata N.E.Br. ex Weim., A. gerrardii Weim. and $A$. woodii

Table 1: Medicinal uses of Aristea ecklonii

\begin{tabular}{|c|c|c|c|}
\hline Medicinal use & Parts of the plant used & Country & References \\
\hline \hline Coughs & Leaf infusions & Eswatini and South Africa & {$[1,7-17]$} \\
\hline Fever & Leaf infusions & Eswatini and South Africa & {$[1,7-9,11,13-17]$} \\
\hline Internal sores & Whole plant & South Africa & {$[1]$} \\
\hline Protective charm & Whole plant & South Africa & {$[10,14,15,17-19]$} \\
\hline Shingles & Whole plant applied topically & South Africa & {$[7,8,9,13,14,15,16,17,22]$} \\
\hline Syphilis & Leaf infusions & South Africa & {$[1,11]$} \\
\hline Venereal diseases & Whole plant & Eswatini and South Africa & \\
\hline
\end{tabular}

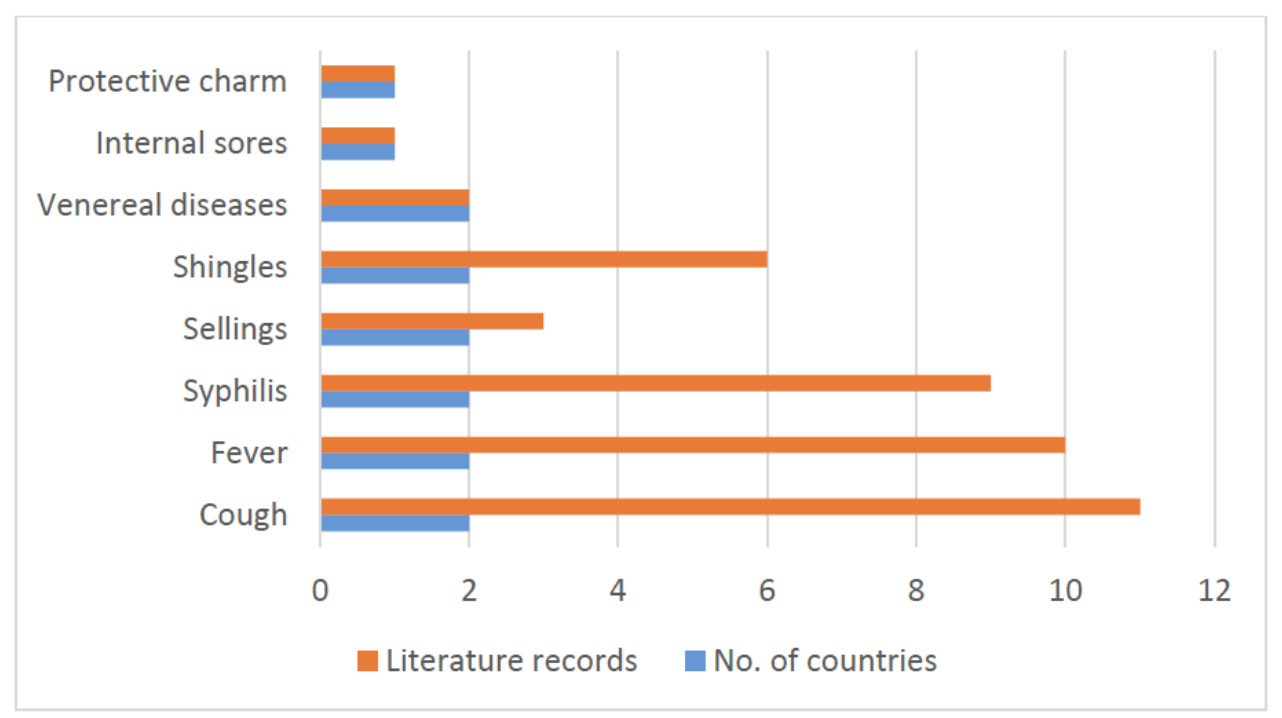

Figure 1: Medicinal applications of Aristea ecklonii derived from literature records. 
N.E.Br. are widely used as herbal medicines in South Africa $[9,20]$.

The ethnopharmacological research of $A$. ecklonii extracts revealed that the species is characterized by quinones and sterols [23]. Plumbagin, 3,3'biplumbagin, 8,8'-biplumbagin, neoisoshinanolone, and sitosterol have been isolated from leaves and rhizomes of the species while $\alpha$-spinasterol was isolated from the rhizomes [23]. Mabona [14] identified the compound plumbagin from leaf extracts of $A$. ecklonii. Similarly, $A$. ecklonii displayed an extensive range of beneficial pharmacological properties that are important for human health effects. Mabona [14] and Mabona et al. [15] evaluated the antibacterial activities of aqueous and dichlomethane: methanol (1:1) leaf and root extracts of $A$. ecklonii using the microtitre plate dilution technique against dermatologically relevant pathogens such as Brevibacillus agri ATCC 51663, Propionibacterium acnes ATCC 11827, Pseudomonas aeruginosa ATCC 27858, Staphylococcus aureus ATCC 25923, methicillin resistant Staphylococcus aureus (MRSA) ATCC 43300, gentamycin - methicillinresistant Staphylococcus aureus (GMRSA) ATCC 33592 and Staphylococcus epidermidis ATCC 2223 with ciprofloxacin as the positive control. The extract showed activities with minimum inhibitory concentration (MIC) values ranging from $0.01 \mathrm{mg} / \mathrm{ml}$ to $8.0 \mathrm{mg} / \mathrm{ml}$ in comparison to MIC values of $0.3 \mu \mathrm{g} / \mathrm{ml}$ to $1.3 \mu \mathrm{g} / \mathrm{ml}$ exhibited by the positive control [14,15]. Mabona [14] evaluated the antibacterial activities of the compound plumbagin isolated from leaf extracts of $A$. ecklonii using the microtitre plate dilution technique against Pseudomonas aeruginosa ATCC 27858, Staphylococcus aureus ATCC 25923, methicillinresistant Staphylococcus aureus (MRSA) ATCC 43300, gentamycin - methicillin-resistant Staphylococcus aureus (GMRSA) ATCC 33592 and Staphylococcus epidermidis ATCC 2223 with ciprofloxacin as a positive control. The compound exhibited noteworthy antibacterial activities with MIC values ranging from 4.0 $\mu \mathrm{g} / \mathrm{ml}$ to $16.0 \mu \mathrm{g} / \mathrm{ml}$ against the tested pathogens in comparison to the MIC values of $0.3 \mu \mathrm{g} / \mathrm{ml}$ to $0.6 \mu \mathrm{g} / \mathrm{ml}$ exhibited by the positive control [14].

Pretorius et al. [24] evaluated antifungal activities of crude extracts of $A$. ecklonii against seven economically important plant pathogenic fungi which included Botrytis cinerea, Fusarium oxysporum, Sclerotium rolfsii, Rhizoctonia solani, Botryosphaeria dothidea, Pythium ultimum and Verticillium dahliae using the agar dilution method to determine the inhibition of mycelial radial growth with carbendazim and difenoconazole (Eria@; 187.5 g/litre EC) as positive controls. The extracts of $A$. ecklonii exhibited $100 \%$ mycelial growth inhibition against tested pathogens and outperformed the inhibition exhibited by the synthetic fungicides carbendazim/difenoconazole used as a positive control [24]. Mabona [14] and Mabona et al. [15] evaluated antifungal activities of aqueous and dichlomethane : methanol (1:1) leaf and root extracts of $A$. ecklonii using the microtitre plate dilution technique against dermatologically relevant pathogens such as Candida albicans ATCC 10231, Microsporum canis ATCC 36299 and Trichophyton mentagrophytes ATCC 9533 with amphotericin B as the positive control. The extract showed activities with MIC values ranging from $0.05 \mathrm{mg} / \mathrm{ml}$ to $4.0 \mathrm{mg} / \mathrm{ml}$ in comparison to MIC value of $1.3 \mu \mathrm{g} / \mathrm{ml}$ to $25.0 \mu \mathrm{g} / \mathrm{ml}$ exhibited by the positive control $[14,15]$. Mabona [14] evaluated the antifungal activities of the compound plumbagin isolated from leaf extracts of $A$. ecklonii using the microtitre plate dilution technique against Candida albicans ATCC 10231 with amphotericin B as a positive control. The compound exhibited noteworthy antifungal activities with MIC value of $2.0 \mu \mathrm{g} / \mathrm{ml}$ against Candida albicans ATCC 10231, and this was the same MIC value exhibited by the positive control [14].

Aristea ecklonii is an important ornamental plant in South Africa recommended for green landscaping to enhance the aesthetic, recreational, and psychological benefits of the coastal belts in South Africa $[25,26]$. Honig [26] argued that $A$. ecklonii looks best when planted in large groups as a groundcover. Aristea ecklonii is also used as a potted plant or outdoors as a mixed perennial border or bed used for courtyard gardens and informal gardens and groundcover. Aristea ecklonii was introduced as an ornamental plant in several countries such as Australia, India, New Zealand, and Sri-Lanka [27-34]. Aristea ecklonii is now listed as a weed in the global collection of weeds by Randall [34]. In Australia, India, New Zealand, and SriLanka, A. ecklonii is listed as an invasive weed, invading coastal scrubland, roadsides, riparian habitats, forest margins and high mountain forests [2734]. Aristea ecklonii is a major invasive alien plant species that was imported into Sri Lanka intentionally as an ornamental plant species [28]. Aristea ecklonii is a potentially serious invader of riparian habitats, coastal areas, roadsides, grasslands, shrublands, woodlands, high mountain forests and margins of evergreen forests. The species produces masses of seeds that are dispersed by water, wind, animals and by vehicles or machinery. The rhizomes of $A$. ecklonii form new shoots when conditions are favourable, 
allowing the plant to survive adverse conditions. The fine and fibrous roots and rhizomes of $A$. ecklonii enable it to form a dense mat in the upper soil and enhancing its capability to form an extensive and dense ground cover, preventing the regeneration of native plant species [35].

\section{CONCLUSION}

Documentation of the medicinal uses, phytochemistry and pharmacological properties of $A$. ecklonii is crucial as this information forms the baseline data required for future research and development of health-promoting and pharmaceutical products. Findings from this study showed that there are still some research gaps in the phytochemistry, pharmacological, and toxicological properties of the species. More rigorous research is required aimed at evaluating various plant parts used as herbal medicines, assessing their phytochemistry, pharmacological, and toxicological properties. Preliminary pharmacological studies have provided supporting evidence for the therapeutic potential of $A$. ecklonii in the management of bacterial and fungal infections. However, there is little or dearth of information on the ethnomedicinal applications of the species in countries such as Burundi, Cameroon, the Democratic Republic of Congo, Mozambique, Rwanda, Tanzania, Uganda and Zimbabwe. Therefore, in-depth ethnobotanical and ethnopharmacological research is required focusing on the medicinal uses, phytochemistry, biological activities and toxicological properties of the species.

\section{CONFLICT OF INTEREST}

No conflict of interest is associated with this work.

\section{ACKNOWLEDGEMENT}

The author would like to express his gratitude to Govan Mbeki Research and Development Centre (GMRDC), University of Fort Hare for financial support.

\section{REFERENCES}

[1] Zondi S. Aristea ecklonii Baker, KwaZulu-Natal National Botanic Garden, 2013. Available from: http://pza.sanbi.org/ aristea-ecklonii, accessed on 16 January 2020.

[2] Hyde M, Wursten B, et al. Aristea ecklonii Baker: Flora of Zimbabwe. 2020. Available from: https://www.zimbabweflora. co.zw/speciesdata/species.php?species_id $=115740$, accessed on 16 January 2020.

[3] Goldblatt P. Iridaceae: Flora Zambesiaca. Flora Zambesiaca Managing Committee, London, 1993; 12(4).

[4] Manning J, Goldblatt P. The Iris family: natural history and classification. Timber Press, Portland, 2008.
Germishuizen G, Meyer NL. Plants of southern Africa: an annotated checklist. Strelitzia 14, National Botanical Institute, Pretoria, 2003

[6] Manning J, Goldblatt P. Plants of the greater Cape Floristic region 1: the core Cape Flora. Strelitzia 29, South Africa National Biodiversity Institute, Pretoria, 2012.

[7] Gerstner J. A preliminary checklist of Zulu names of plants with short notes. Bantu Stud 1939; 13(1): 49-64. https://doi.org/10.1080/02561751.1939.9676090

[8] Hutchings A. Zulu medicinal plants. University of Natal Press, Pietermaritzburg, 1996.

[9] Hutchings $\mathrm{A}$, Scott $\mathrm{AH}$, et al. Zulu medicinal plants: an inventory. University of Natal Press, Pietermaritzburg, 1996.

[10] Ngwenya MA, Koopman A, Williams R. Zulu botanical knowledge: an introduction. National Botanical Institute, Durban, 2003.

[11] Long C. Swaziland's flora: Siswati names and uses Mbambane, Swaziland: Swaziland National Trust Commission, 2005. Available from: http://www.sntc.org.sz/ index.asp, accessed on 14 December 2019].

[12] McGaw LJ, Lall N, et al. The potential of South African plants against Mycobacterium infections. J Ethnopharmacol 2008; 119: 482-500. https://doi.org/10.1016/j.jep.2008.08.022

[13] Wentzel J, Van Ginkel CE. Distribution, use and ecological roles of the medicinal plants confined to freshwater ecosystems in South Africa. Water Research Commission, Pretoria, 2012.

[14] Mabona U. Antimicrobial activity of southern African medicinal plants with dermatological relevance. MSc Dissertation, University of the Witwatersrand, Johannesburg, 2013.

[15] Mabona U, Viljoen A, et al. Antimicrobial activity of southern African medicinal plants with dermatological relevance: from an ethnopharmacological screening approach, to combination studies and the isolation of a bioactive compound. J Ethnopharmacol 2013; 148(1): 45-55. https://doi.org/10.1016/j.jep.2013.03.056

[16] Lall N, Kishore N. Are plants used for skin care in South Africa fully explored? J Ethnopharmacol 2014; 153: 61-84. https://doi.org/10.1016/j.jep.2014.02.021

[17] Sagbo IJ, Mbeng WO. Plants used for cosmetics in the Eastern Cape province of South Africa: a case study of skin care. Phcog Rev 2018; 12: 139-56. https://doi.org/10.4103/phrev.phrev 918

[18] Pattanayak S. Healthcare system using succulent parts of plants. Calcutta Block and Print, Kolkata, 2019.

[19] Sagbo IJ, Mbeng WO. Are plants used in the Eastern Cape province for cosmetics fully commercialized? Indian J Pharmacol 2019; 51(3): 140-9. https://doi.org/10.4103/ijp.IJP 26218

[20] Cunningham AB. African medicinal plants: setting priorities at the interface between conservation and primary health care. People and Plants Working Paper 1, UNESCO, Paris, 1993.

[21] Hulme MM. Wild Flowers of Natal. Shuter and Shooter, Pietermaritzburg, 1954.

[22] Mabona U, Van Vuuren SF. Southern African medicinal plants used to treat skin diseases. S Afr J Bot 2013; 87: 17593.

https://doi.org/10.1016/j.sajb.2013.04.002

[23] Kumar V, Meepagala KM, Lalasubraminiam S. Quinoid and other constituents of Aristea ecklonii. Phytochem 1985; 25: 1118-9. https://doi.org/10.1016/S0031-9422(00)83204-5

[24] Pretorius JC, Zietsman PC, Deksteen D. Fungitoxic properties of selected South African plant species against plant pathogens of economic importance in agriculture. Annals Appl Biol 2002; 141: 117-24. https://doi.org/10.1111/j.1744-7348.2002.tb00203.x 
[25] Diederichs N, Nichols G, Van Niekerk M. Green landscaping guideline. eThekwini Municipality, Durban, 2009.

[26] Honig M. Indigenous plant palettes: an essential guide to plant selection. Quivertree Publications, Cape Town, 2014.

[27] Csuches S, Edwards R. Potential environmental weeds in Australia. Queensland Department of Natural Resources, Brisbane, 1998.

[28] Marambe B, Bambaradeniya C, et al. Human dimensions of invasive alien species in Sri Lanka. In: McNeely JA (Ed.), The great reshuffling: human dimensions of invasive alien species. IUCN, Cambridge 2001; pp. 135-144.

[29] Randall R. Garden thugs, a national list of invasive and potentially invasive garden plants. Plant Prot Quart 2001; 16(4): 138-71.

[30] Froude VA. Biological control options for invasive weeds of New Zealand protected areas. Science for Conservation 199. Department of Conservation, Wellington, 2002.
[31] Davies RB. Wild spirits: the remarkable heritage of Waikumete Cemetery is very much alive, in its joyous array of wildflowers. New Zealand Garden 2014; 37-41.

[32] Kumar KK. A checklist to the vascular flora of Anamudi Shola National Park, Munnar, Idukki district, Kerala. Scientia 2015 11(1): 51-73.

[33] Arjun CP, Anoop VK, et al. Invasive plants: A boon or bane to the Lepidopteron fauna: Conservation and management plan suggestions. Kongunadu Res J 2017; 4(1): 148-60. https://doi.org/10.26524/krj192

[34] Randall RP. A Global Compendium of Weeds. Department of Agriculture, Perth, 2017.

[35] Csurhes S. Pest plant risk assessment blue stars Aristea ecklonii biosecurity. Queensland Department of Primary Industries and Fisheries, Queensland, 2008.

Received on 11-02-2020

Accepted on 04-03-2020

Published on 12-03-2020

DOI: https://doi.org/10.29169/1927-5951.2020.10.02.1

(C) 2020 Alfred Maroyi; Licensee SET Publisher.

This is an open access article licensed under the terms of the Creative Commons Attribution Non-Commercial License (http://creativecommons.org/licenses/by-nc/3.0/) which permits unrestricted, non-commercial use, distribution and reproduction in any medium, provided the work is properly cited. 